\title{
THE USE OF TRADITIONAL MUD-BASED MASONRY IN THE RESTORATION OF THE IRON AGE SITE OF SALŪT (OMAN). A WAY TOWARDS MUTUAL PRESERVATION
}

\author{
S. Bizzarri ${ }^{1,2}$,, M. Degli Esposti ${ }^{1,3}$, C. Careccia ${ }^{1,4}$, T. De Gennaro ${ }^{1,4}$, E. Tangheroni ${ }^{1}$, N. Avanzini ${ }^{1,5}$ \\ ${ }^{1}$ Italian Mission to Oman (IMTO) - (stebzz, michele.degliesposti, elisatangheroni, avanzininicolo, caterinacareccia.ing, \\ degennaro.tiziana)@gmail.com \\ 2 DZAA Architects \\ ${ }^{3}$ Membre associé, UMR 6566, CReAAH (Centre de Recherche en Archéologie, Archéosciences, Histoire), Université de Rennes (France) \\ ${ }^{4}$ Italian Ministry of Cultural Heritage and Activities and Tourism (MIBACT) - (caterina.careccia, tiziana.degennaro)@ beniculturali.it \\ ${ }^{5}$ Adrianea Academy of Architecture and Archaeology
}

\section{Commission II - WG II/8}

KEY WORDS: Mudbrick walls, Traditional masonry, Mud plaster, Earthen heritage

\begin{abstract}
:
The archaeological record of the Sultanate of Oman speaks of the use of mudbricks (adobes) and mud plaster as key building materials over a long chronological range from the Early Bronze Age (late 4th / 3rd millennium BC) to the Late Iron Age at least (first centuries BC). Traditional earthen architecture perpetuated this scenario until modern times when the discovery of oil brought along deep transformations in the local economy and way of living. This long-lasting tradition has provided the necessary means to cope with the problem of mudbrick structures conservation on the prominent archaeological site of Salūt, in central Oman, where substantial mudbrick walls were discovered, dating to the second half of the second millennium BC and beyond. In fact, exploiting the life-long experience in mud-based masonry of a local mason turned out to be the best (and arguably only) way of consolidating and protecting the ancient structures. This strategy not only is definitely a sustainable one, as only readily accessible and largely available natural materials were employed, but it also helps to revive a locally rooted skill that seriously risks being forgotten due to the lack of interest in younger generations. With this aim in mind, a survey and recording of the local terminology connected with the tools and techniques of mud-based masonry were also carried out. This paper will account for the various stages of the work that led to the final restoration and conservation of the site. The use of different media - pictures, drawings, videos - reflects the comprehensive approach towards this fundamental issue. The recent development of the project included the preparation of mud plasters made following different procedures in order to achieve a better visual impact and a lower static load on the structures.
\end{abstract}

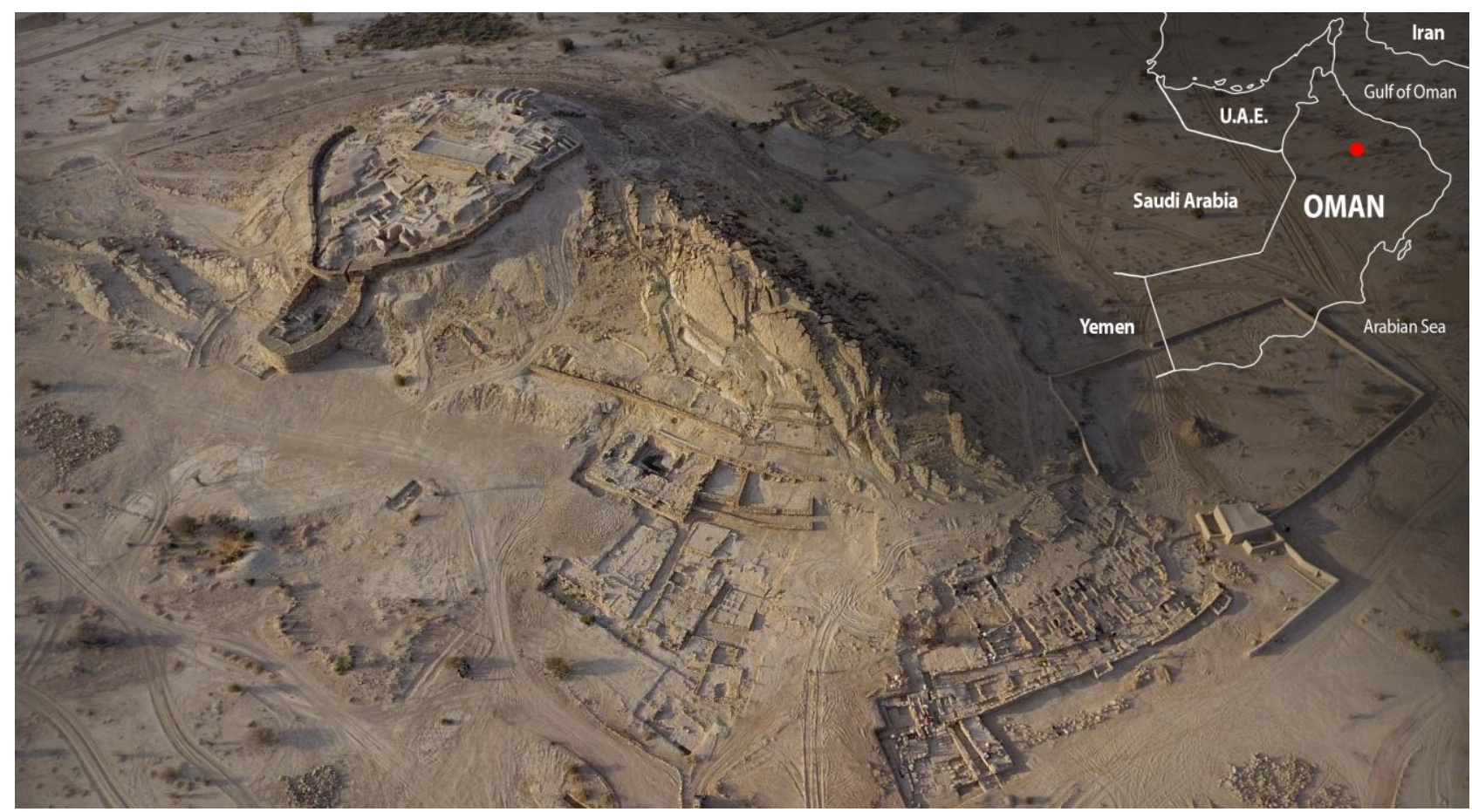

Figure 1. The Archaeological Site of Salūt.

\footnotetext{
* Corresponding author
} 


\section{INTRODUCTION}

The prominent Iron Age (c. 1300-300 BC) site of Salūt, in central Oman, has been the focus of the research of the Italian Mission to Oman (IMTO) of the University of Pisa from 2004 to early 2019. Since the early years of this progressively expanding project, conservation and possible reconstruction of the ancient monuments have been among the main aims, with the specific goal of developing a presentation of the site to the wider public and to foster locals' appreciation and involvement.

While initial work mainly dealt with dry stone walls, the restoration and conservation of mudbrick structures became more and more essential as wider portions of the site were unearthed and revealed mudbrick floors and walls preserved to remarkable heights.

A multidisciplinary approach, primarily including stringent collaboration between architects and archaeologists, has been instrumental in achieving satisfactory results. Since this project aims to follow UNESCO guidelines an in-depth study and discussion of the original nature, materials and dimensions of the discovered structures is, in fact, essential.

This approach provided the basis for implementing a whole series of new technologies for digital documentation and elaboration that have developed with unprecedented rapidity over the last few years, namely including digital photography, 2D photogrammetry and structure-from-motion 3D reconstructions that often used aerial footage as raw data.

The restoration process could thus build upon this comprehensive work of documentation and understanding of the ancient architectural remains. Fundamental to our idea of restoration was the use of widely and readily available materials that need not be sourced far from the site and are, therefore, highly sustainable both economically and in terms of resource consumption; not to mention their correspondence with their ancient counterparts. Moreover, the nature of the work itself resulted in being best for the application of the traditional, mudbased masonry, the survival of which is strongly endangered by the gradual loss of interest of the young generations.

\subsection{The ancient oasis of Salūt and the archaeological background for earthen construction in SE Arabia}

Mud-based construction (including mudbricks and mud-based plaster and binder), together with stone building, has represented the key building technique in South East (SE) Arabia since at least the late 4th/very early 3rd millennium BC and up until the second half of the 20th century CE when the economy and daily life of the Arabian and Gulf countries was revolutionised by the discovery of oil.

Located in the heart of the Oman Peninsula, the ancient oasis of Salūt bears witness to 5000 years of human occupation at the least and hosts evidence related to the main periods of SE Arabian history (Degli Esposti, 2015; Degli Esposti et al., 2018). As such, it offers the possibility of examining the evolution of earthen architecture throughout this long time frame. The first period of intense occupation at Salūt can be dated back to c. 2500 BC (Early Bronze Age), when three monumental so-called 'tower' sites characteristic of the period - were established in the plain. The architecture of these sites entailed the use of large to megalithic blocks for the main and outer walls, while mudbrick architecture was used (in some cases) for inner partitions. In other areas of SE Arabia, where stone is not available for construction, even the outer structures of these monuments were erected with the use of substantial quantities of mudbricks.
After a period of reduced human settlement (Middle Bronze Age, c. 2000-1300 BC), the Early Iron Age (c. 1300-300 BC) saw a remarkable demographic increase in the region and new settlements appeared in large numbers. At Salūt, after a few centuries of apparent abandonment, the establishment of a prominent Early Iron Age site on and around one small hill in the middle of the plain involved the extensive use of mudbrick features, which were the focus of the restoration programme discussed here. Walls were built either of mudbricks above a stone base or entirely of mudbricks, bound with clay and originally plastered with mud-plaster. Floors were also often made with mudbricks. Mudbricks and brick fragments were also used in the buildup of the supporting structure for the huge fortification that formed the elevated part of the site (Degli Esposti, Condoluci, 2018; Condoluci 2018).

Earthen architecture continued to be in use in the region even after the end of the Early Iron Age and has represented the main construction technique until modern times when cement became widely used. Several traditional villages are still visible, some still at least partially inhabited, that document this long-lasting tradition. In the Salūt oasis, post-Early Iron Age occupation is mainly borne out by a Late Iron necropolis comprising underground chamber tombs with stone and mudbrick walls. Later, during the Islamic period, testimony of earthen architecture is only provided by graves, while domestic features are lost.

\section{MULTI-MEDIAL DOCUMENTATION AND VIRTUAL RECONSTRUCTION AS COMPANION TOOLS FOR THE RESTORATION PROCESS}

In the last few years significant improvements in architectural and topographic surveys have taken place allowing the combined use of the classic topographic ground-point technique with large-scale photography for the creation of 3D models. Specifically, the great versatility in the use of point clouds made possible by the use of drones and professional cameras permits modelling a range of subjects spanning entire areas to small objects 'in situ', i.e., easily shifting from the macro to the micro-scale.

By exploiting these opportunities, the excavation areas at Salūt were surveyed daily through wide-area and detailed flights, adding to the aerial footage, and thus obtaining the results of field-level photographic documentation.

It is clear that this kind of approach has significantly improved the efficiency of the archaeological workflow, as excavation can proceed quickly without waiting for the long sessions of traditional field topography and manual drawing. Direct work on the field remains, however, essential for providing the coordinates of the ground-points.

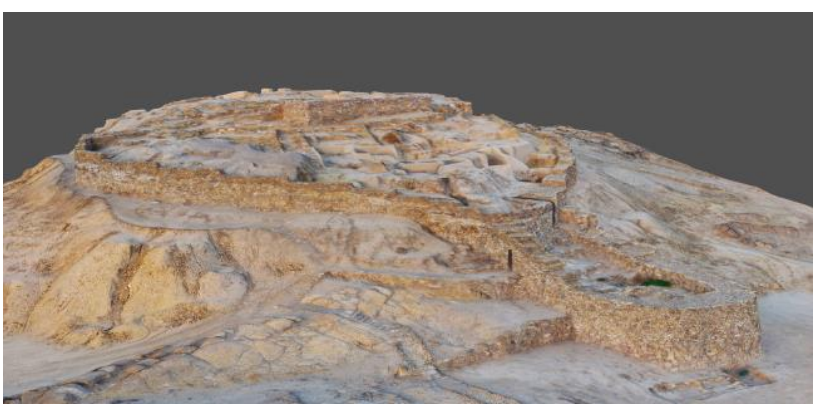

Figure 2. Husn Salūt, high definition 3D model. 
Furthermore, through the use of digital modelling tools such as Digital Terrain Model (DTM) and Digital Elevation Model (DEM), it was possible to remove redundant data from the terrain models, thus highlighting the structures that would conversely be difficult to visualize in their complexity even after accurate field survey.
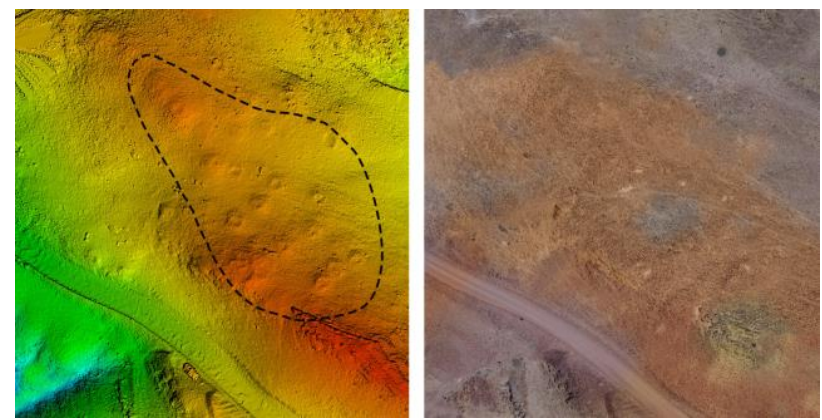

Figure 3. The DEM reveals decayed tombs on Jabal Salūt (JS4) that would remain hidden in the orthophoto.

The 3D reconstructions remarkably supported the restoration process as well, allowing correct analysis of the structural condition and making accurate simulations of the final result of conservation and consolidation activities possible.

Terrain modelling also allowed for a reliable assessment of the slopes affected by the water flows, facilitating the study for the construction of drainage channels with a low visual impact, compatible with the aspect of the site.

Together with the use of point clouds-based modelling, video footage was identified as a useful tool for creating a database aimed at the preservation of the technical know-how implied in the hand-made realisation of mudbrick and plaster, now at risk of disappearing. In fact, by implementing a sustainable approach to the conservation of mudbrick walls and floors, over the years we have gained an in-depth view of the local, traditional mud processing techniques for the making of the plaster to protect the walls.
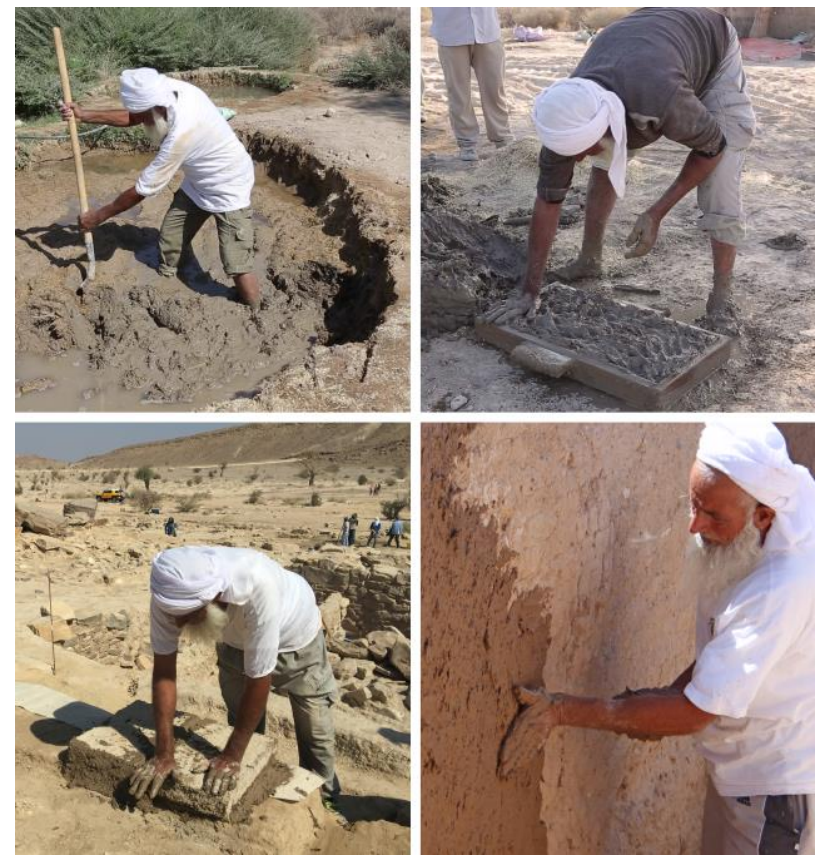

Figure 4. Mubdricks preparation, laying and wall plastering.
To this end, we accurately documented the work of our local mason by recording some interviews and shooting videos of every step of the production process, taking care to detail the use of the different tools together with the local terminology associated with them. Once re-organized and edited, this material could also support the dissemination of the site.

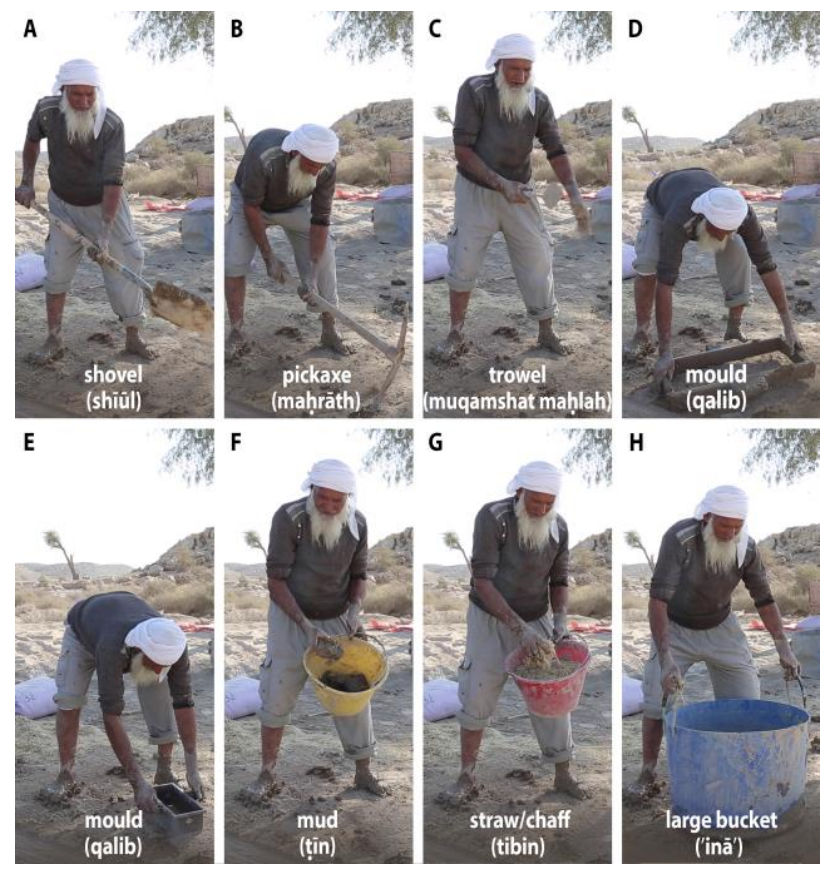

Figure 5. The different tools used throughout the mudbrick production process and their transliterated (local) Arab name.

An accurate documentation is essential for the planning of conservation work and for the implementation of the guidelines for subsequent maintenance. Moreover it becomes an integral part of the site and a tool for understanding its past, its present and the future needs.

\section{THE CONSERVATION STRATEGY FOR SALŪT}

Restoration activities have been carried out on both stone walls and mudbrick walls, obviously following different and specific procedures, while adhering to the basic tenets of the modern conservation, such as the UNESCO and ICOMOS, guidelines:

- Promoting minimum intervention: summed up by the maxim 'do as much as necessary and as little as possible'.

- Ensuring the reversibility of interventions: being able to reestablish the previous condition avoiding irreversible interventions.

- Making the intervention recognizable and respectful: as similar as possible to the original, without running into a fake original (Petzet, 2004).

For mudbrick elements, specific procedures have been adopted to consolidate masonries, floors, foundations or simply to remake surfaces, using local traditional techniques and materials suitable and found on-site. All the operations were materially carried out exclusively by Mr. Massaoud Al-Khīarī, an old Omani craftsman, expert in traditional mudbricks and mudplaster working, with the coordination of the architectural conservation team. 
All interventions on the site were scheduled according to work phases. In the first phase, a general view of the nature of the area was acquired and the condition of the structures brought to light during the previous excavation campaigns was surveyed in order to assess the current state of degradation and identify critical restoration and conservation issues (Bizzarri, 2015).

\subsection{Decay and damage}

As is well known, earth is one of the most widely used construction materials in the world but it is also one of the most vulnerable and the heterogeneity of earthen materials and construction systems makes it difficult to classify general decay processes and their related treatments (Rainer, 2008).

The second phase of the restoration work entailed the understanding of the deterioration causes, with the aim of achieving a decay mapping, a necessary step before a comprehensive intervention program and a conservation plan of the site.

The causes of deterioration of these structures can be classified as intrinsic when they are associated with the materials' composition or with the construction technique and extrinsic when external factors such as water, wind and other environmental and contextual factors play a role.

The most common types of deterioration observed on the mudbrick structures of Salūt seem to be related to wind and rain erosion (extrinsic factors). Aeolian erosion is further facilitated by the absence of roofs or shelters and, likewise, unanticipated heavy rains can fall upon the not well-protected structures thus accelerating decay.

Generally such damage tends to occur at the top of the wall (Doat et al., 1983) and on the entire surface, where erosion occurs in the form of non-structural damage like detachment, disaggregation, flaking and cracking. At the bottom of the wall, in case of water penetration/infiltration and/or rising damp creating a basal erosion, the inefficiency of the protective coating can cause structural damage leading to upper wall displacement, leaning and collapse (Rainer, 2008).

Water from flash-flooding is certainly the major factor causing deterioration at the base of the walls, while the capillary rise and rains prompt erosion along the top of the walls, thus creating deep ridges and gullies.

The study of the site and the analysis of the different causes of degradation led to two ways to minimize erosion and protect the earthen structures:

- Modify the slopes of the site in order to get rid of standing water and minimize surface runoff.

- Insulating the structures against the extrinsic factors by protecting the exposed surfaces with materials such as soil, mudbricks and mud-plaster (Dehkordi et al., 2008).

First of all, the issue of rainwater drainage was tackled by identifying the naturally formed channels through which water tends to drain. These channels were then more neatly shaped and filled with drainage material, facilitating the waters to flow downstream and, at the same time, not altering the visual appearance of the site (Bizzarri, 2015).

\subsection{Conservation and traditional methods}

As regards the conservation of mudbrick structures, two different cases were identified:
1. Collapsed mudbrick masonry, where only the foundation row survived, generally found in a fair state of preservation.

2. Mudbrick masonry intact in all its original height, even if not in a good state of conservation.

In order to achieve the conservation of the discovered structures and to provide a clear explanation of the site to the wider public, restoration also included partial or total reconstructions.

The first step was the set-up of a mudbrick production area near the site, also including the preparation of the mud-and-straw mortar. The latter was continuously mixed and kept wet so as to be ready to be brought on the intervention place when needed.

In fact, suitable mud, mixed with straw, needs to be stirred for a couple of days; it is then brought on-site and mixed again with additional water to achieve the right consistency. The mixture is then spread, coat after coat, onto the mudbrick walls. The sun dries the plaster in two/three days, giving it a solid structure and a light brown colour (Bizzarri, 2015).

Mudbricks were prepared in advance to be used in integrations or reconstructions and the 'soft' nature of the mudbricks has allowed the mason to cut them to the required, smaller dimensions as the work proceeded, in order to:

- Ensure physical compatibility between the original and the restored section and sufficient thickness to protect the original section from erosion (Dehkordi et al., 2008).

- Increase the surface of bricklaying.

- Make the intervention 'recognizable and respectful'.

\subsection{The restoration of the mudbrick walls and floors}

The restoration of the collapsed mudbrick walls followed these steps:

1. Preliminary cleaning activity, manual removal of vegetation and soil.

2. Manual removal of unstable and collapsed mudbrick portions to provide a solid basis for reconstruction.

3. Cleaning of the base and placing of a geotextile layer to mark the separation between the old part and the reconstructed one.

4. Rebuilding of the missing part of the walls with new mudbricks made on-site.

5. Plastering of the surfaces with mud-and-straw layers to protect the underneath structure.

In particular, for steps 3 and 4 the layer of geotextile was covered with a layer of compressed earth, followed by layers of mudbricks and compressed earth up to the required height and the top of the wall was covered with a mud-and-straw plaster layer sloped at the efficient incline to shed water.

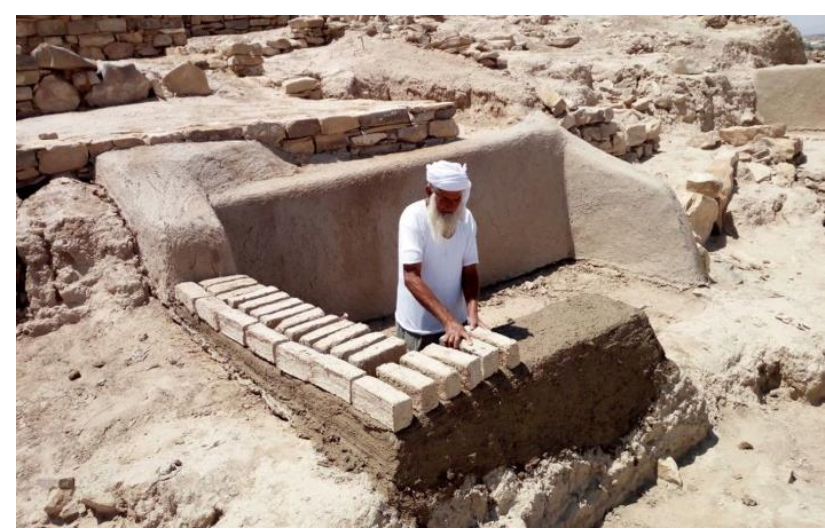

Figure 6. Mr. Massaoud Al-Khīarī rebuilding the missing part of the walls with new mudbricks made on site. 
In order for the mudbrick masonries to remain intact over all of their height, the restoration process included: removal of the old and deteriorated mud plaster, cleaning of the surface of the mudbrick structure, filling of possible lacunas with small and medium stones set in the same mud used for plastering, and spreading of new mudand-straw plaster, coat after coat, on the wall.

The same materials and methods were used for the mudbrick floors. First, the surface of the floor was levelled using compressed earth. This was covered with a layer of geotextile topped by an additional layer of bricks. A thin layer of soil was then used to fill the gaps between the mudbricks and to create a slight slope necessary to divert surface water, when possible.

Despite mudbrick structures being recognized as very difficult to preserve, at Salūt the apt strategy to handle this problem was set up involving traditional skills deeply rooted in local house building, using local and sustainable materials and plastering the walls with fresh mud prepared near the site, thus using the same sandy clay used for the original mudbricks and mud plaster.

This procedure has proven to be extremely efficient, particularly when connected with the definition of a longer-term maintenance plan for the site. In fact, the lack of regular maintenance is one of the main factors that accelerate the decay of earthen structures. However, thanks to this conservation strategy, restored structures suffered no significant damage from the heavy rains occurring at the site in recent years.

\section{EMPIRICAL TESTS ON PLASTER MIX: ACHIEVING AN ADEQUATE INTERPRETATION FOR THE CONSERVATION OF THE EARTHEN STRUCTURAL HERITAGE OF THE SITE}

Plastering had to follow the protocol established by the IMTO, which comprises some constraints:

- The new interventions should be clearly distinguishable from the original parts of the structures.

- Traditional technologies should be implied, thus using locally available resources.

- Results should reduce the necessity of maintenance works.

To meet these purposes, a series of plastering tests were conducted, aiming to:

- Achieve a good match with the composition of the original material.

- Obtain a similar evo-transpiration capacity as the original material.

- Obtain a similar (or in any case not higher) strength as the original material.

The ultimate goal of the research was to obtain a mud-based mix suitable for the production of plaster and mortar that could be stabilized with a lower quantity of straw than the one produced by our mason, in order to minimise its aesthetic impact on the finishing.

The absence of a dedicated budget, time constraints and the limited diversity of locally available materials affected the number and quality of the tested combinations.

The soil was sampled from different locations on the site with the aim of providing useful data to identify different compositions and to verify its suitability as a construction material.
Three macroscopically different soils were sampled, cleansed from organic elements: $T 1$ from the northeastern area of the Iron Age settlement; $T 2$ from the western area; and $T 3$ from the lower slope of the hills standing northeast of the Iron Age site, where Bronze Age tombs were being excavated.

Two kinds of soil were also sampled from the area surrounding the archaeological sites: 'soil S', which sedimentation analysis (Figure 1) indicated to be composed of $100 \%$ fine sand, with a reddish-golden colour; and 'soil G', composed of 52\% gravel, $32 \%$ sand and $16 \%$ loam, with a grey colour.

The following preliminary analyses were carried out on samples T1, T2 and T3:

- Visual examination: appearance, colour, size of the components.

- Tactile examination: testing the behaviour of the soil to check whether it is sandy or rough and abrasive to the touch, silty or fine and easy to pulverise, clayey or difficult to break, fine and sticky.

- Hand washing test: the more clayey the soil is, the more difficult is to clean up off one's hands after handling it.

- Cohesion and resistance test: forming a sphere of a $6 \mathrm{~cm}$ diameter that, once dried, is dropped to the ground from a known height.

- Consistency test: forming a 2,5 cm diameter 'cigar' with moist soil and hanging it little by little. If the cigar breaks between 10 and $15 \mathrm{~cm}$-and in any case above $5 \mathrm{~cm}$ - the earth is suitable for building. If breakage occurs below 5 $\mathrm{cm}$, the earth is more sandy; conversely, if it breaks above $15 \mathrm{~cm}$ the soil is too clayey ('fat') and the addition of a temper is necessary (Figure 7).

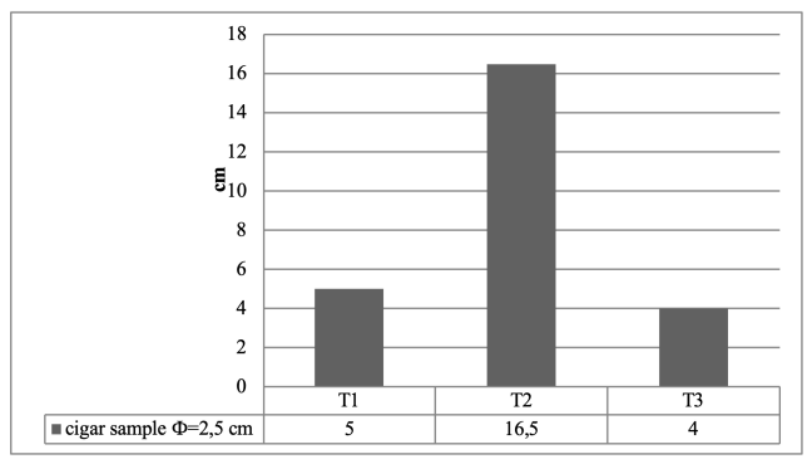

Figure 7. Consistency test on soils T1, T2, T3.

- Granulometric analysis by sedimentation (conducted also on samples S, G): putting a known quantity of soil into a bottle full of water in order to evaluate the percentage of solid elements sedimented over one day (Figure 8).

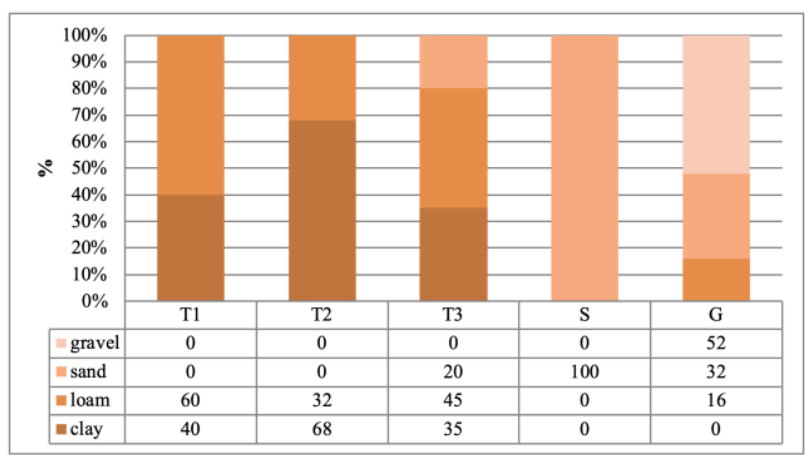

Figure 8. Sedimentation tests on soils T1, T2, T3, S, G. 
- Shrinkage and crack test: laying a layer of soil on a flat surface and checking the number and extent of the cracks that form during drying. Stone surfaces of about $20 \times 15$ $\mathrm{cm}$ were chosen for this test and an earth layer $2,5-3 \mathrm{~cm}$ thick was laid down above them and kept wet over the first two-three hours by frequently spraying water. Samples were then covered with a plastic sheet for onetwo days to face the hot temperature on the site (it must be noted that this last operation is clearly not possible when actually using the plaster for construction, while repeated pouring of water is commonly carried out by our mason).

\begin{tabular}{|l|l|l|r|r|}
\hline \multicolumn{5}{|c|}{ shrinkage and crack test } \\
\hline & $\begin{array}{c}\text { crack }> \\
4 \mathrm{~mm}\end{array}$ & $\begin{array}{c}\text { passing- } \\
\text { through } \\
\text { crack }\end{array}$ & $\begin{array}{c}\text { crack } \\
\text { max } \\
(\mathrm{mm})\end{array}$ & fragments \\
\hline soil type & deep & frar & 8 & 5 \\
\hline T1 & yes & yes & 6 & 15 \\
\hline T2 & yes & yes & 3 & 2 \\
\hline T3 & yes & no & & \\
\hline
\end{tabular}

Figure 9. Shrinkage and crack test on soils T1, T2, T3 (20x $15 \mathrm{~cm}$ surface).

The tests indicate that $\mathrm{T} 1$ comprises loam as the main component plus a low percentage of clay. All the tests confirm a certain degree of cohesiveness due to its water permeability. For this reason, it is subject to swelling and shrinkage. A bad performance in the consistency test confirmed the insufficient content of binder (i.e., clay) in its composition. Overall, this soil is not suitable for construction without any addition of corrective components.

Tests on soil T2 indicate it is composed mainly of clay with a low loam content. Although similar to $\mathrm{T} 1$ it is subject to swelling and shrinkage, due to a high degree of cohesiveness linked to water permeability. The consistency test confirmed the prevailing percentage of binder in its composition, which makes this soil 'fat' and not suitable as a construction material without the addition of any sort of temper.

Finally, soil T3 showed it comprised a high percentage of loamsand with a low percentage of clay. All the tests show that this soil is also subject to shrinkage, although less extensive than the other samples. However, this soil also needs the addition of balancing components in order to become suitable as a construction material.

The following step was the 'correction' of the analysed soil composition with the addition of natural tempering material available on the site. Different mixtures were tested in order to understand if performance improvements could be achieved by balancing the components.

The tests were made using $27 \times 57 \mathrm{~cm}$ mudbricks as standard surface, scrubbed clean and moistened before each application to prevent water from being drained out of the plaster layer into the brick. The layers were forcefully applied by hand in order to increase adherence of the plaster to the brick surface. Even in this case, test layers were sprayed with water once or twice during the first hours after being laid down and covered with a plastic sheet for one-two days.

The results of these tests were not optimal but highlighted the necessity to increase the sand component in sample T2, which can conversely be used as a binder due to its high clay content.
Further tests were made to improve the quality of earthen plaster by balancing the lacking (sandy) components. In fact, better performance of mud-based plaster and mortar is achievable by controlling the quantity of the sand fraction in the soil, for example keeping a ratio of no less than three parts of sand to one of clay, for example. This helps reduce cracks without compromising cohesion (Ruskulis, 2009).

New samples were prepared:

- Sample $1 b$, made mixing 1 part $\mathrm{T} 2+3$ parts $\mathrm{S}$. Once dried, cracks could be completely closed with a simple, manual surface friction treatment with water. On part of the sample a second, very fluid coat was applied so as to experiment different a finishing. This sample showed a weak cohesion and a poor resistance to washing;

- Sample 3b, made mixing 1 part T2+3 parts G. Cracks were completely closed with the secondary manual treatment with water. This sample showed good cohesion and reasonable resistance to washing;

- Sample $4 b$ made mixing 1 part $\mathrm{T} 2+1$ part $\mathrm{S}+1$ part $\mathrm{G}$ and tempered with a small amount of straw and gravel $(0 \mathrm{~mm}<\phi<20 \mathrm{~mm})$, in a way that their presence was not visually predominant on the surface finishing but could anyhow help to avoid cracks and increasing cohesion and resistance to washing away. Cracks were completely closed with the secondary manual treatment with water. This sample showed good cohesion and reasonable resistance to washing;

- Sample $4 b$ made mixing 1 part $\mathrm{T} 2+1$ part $\mathrm{S}+1$ part $\mathrm{G}$ and tempered with a small amount of straw and gravel $(0 \mathrm{~mm}<\phi<20 \mathrm{~mm})$, in a way that their presence was not visually predominant on the surface finishing but could anyhow help avoiding cracks while increasing cohesion and resistance to washing away. Cracks were completely closed with the secondary manual treatment with water. This sample showed good cohesion and reasonable resistance to the washing, together with an ideal finishing and colour surface. For such reasons it was selected for further tests.

Additional improvement of the plaster's stability could be achieved by adding small quantities of other binders, such as in the following test samples:

- Sample 5b. made mixing 1 part $\mathrm{T} 2+1$ part $\mathrm{S}+1$ part $\mathrm{G}$ and tempered with 1 small trowel of grey Portland cement, gravel $(\phi<2 \mathrm{~mm})$ and little straw. Cracks were not completely closed with the secondary hand treatment with water. This sample did not show a good cohesion and resistance to washing. Moreover, the colour of the finishing turned too greyish to be suitable for our purpose;

- Sample $6 b$, made mixing 1 part $\mathrm{T} 2+1$ part $\mathrm{S}$ and tempered with 1 part of industrially produced sarooj, gravel $(\phi<2 \mathrm{~mm})$ and little straw.The sample showed deep cracks with remarkable detachments and, unexpectedly, it didn't show a really good cohesion and resistance to the washing, at least some days after;

- Sample $7 b$ made mixing 1 part $\mathrm{S}$ and tempered with 1 part of sarooj, gravel $(\phi<2 \mathrm{~mm})$ and little straw. The sample presented cracks with little detachments and it didn't show good resistance to the washing. For such reasons it was selected for further tests, adding a gravel temper.

The final step was implementing the tests on the vertical and large surface of a recently built mudbrick wall.

Traditionally, mud plasters are often applied in one coat both internally and externally. If applied in two coats, the first can contain more clay, even if this leads to the development of more 
cracks, while the second is sandier and is applied in a thinner layer. This second coat will close the cracks in the first one, provided the surface has been lightly wetted before plastering. The more sustainable methods at Salūt appeared to be the use of two coats, considering the availability of clay soil on the site and the scarcity of sand.

First, the wall surface was cleaned and moistened. The first plaster coat was forcefully applied by hand with a thickness of 20 $\mathrm{mm}$, in order to create a naturally wrinkled surface to provide good bonding for the second coat. It was important the plaster was sprayed with a coat twice or three times a day with water during the first days to reduce cracking. Plastic sheets were also used to shade the wall.

Based on the results of the tests described above, the following mix was used for the wider-area plaster tests:

- Sample A, coat 1: (Figure 10, top left): 1T2+ 1S+ $1 \mathrm{G}(0<\phi<2 \mathrm{~mm})+1 / 8$ straw approx. $+1 / 8$ gravel $(2<\phi<20 \mathrm{~mm})$ approx;

This was compared with a sample with the same composition as the one normally used by our mason in the restoration works:

\section{- Sample B, coat 1: made of $1 \mathrm{~T} 2+1 / 2$ straw approx.}
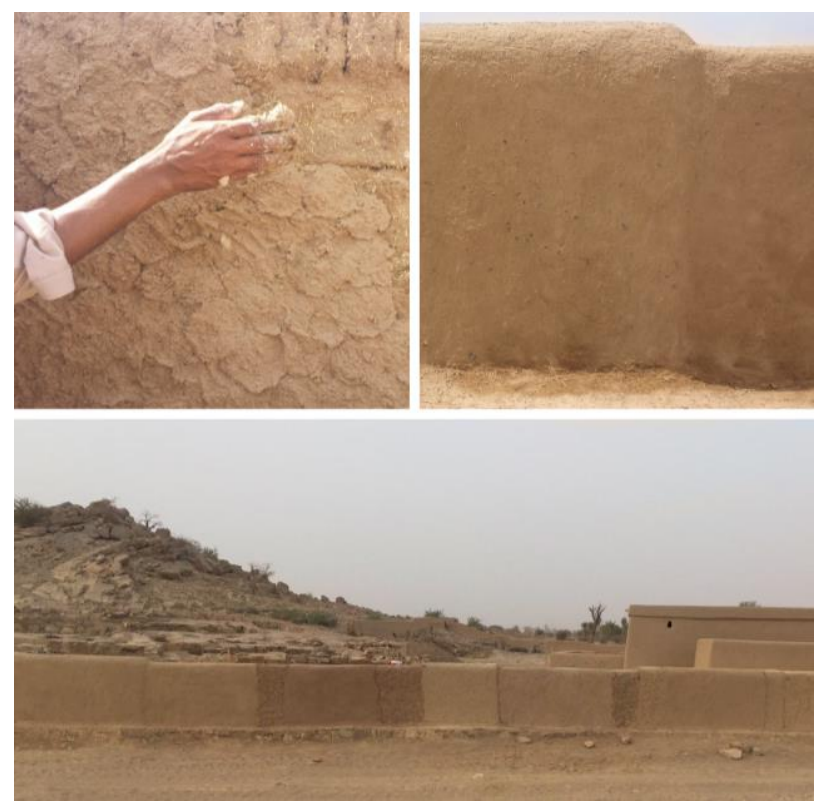

Figure 10. Plaster tests on a new mudbrick structure, from top left: Sample A, coat 1; Sample 1, coat 2; Samples on the west side of the wall.

For the second coat, a mix with a majority of sand content was used and only applied when the first coat was dry, with a thickness of 10-15 mm and then smoothed by hand to get an even finish. Also, in this case, the plaster was accurately kept wet for a few days and shaded to reduce cracking, especially for samples that tested the addition of binders such as sarooj and chalk.

In fact, samples made by experimenting the use of sarooj, chalk and cow dung were made to understand their waterproofing contribution and they were selected because these are traditionally used easily available materials. For all these samples small cracks were fixed with one surface friction treatment once the plasters were dry.
The following mixes were tested for the second coat (visible in Figure 10 bottom left to right):

- Sample 1, coat 2 (also Figure 10, top right): $1 \mathrm{~T} 2+1,5 \mathrm{~S}+1,5$ $\mathrm{G}(0<\phi<2 \mathrm{~mm})+1 / 8$ straw approx. $+1 / 8$ gravel $(2<\phi<20 \mathrm{~mm})$ approx.;

- Sample 2, coat 2: 1 sarooj+ 1,5 S + 1,5 G $(0<\phi<2 \mathrm{~mm})+1 / 8$ straw approx. $+1 / 8$ gravel $(2<\phi<20 \mathrm{~mm})$ approx;

- Sample 3, coat 2: $1 \mathrm{~T} 2+3 / 2 \mathrm{~S}+1 / 2 \mathrm{G}(0<\phi<2 \mathrm{~mm})+1 / 2$ sarooj+ $1 / 2$ white chalk;

- Sample 4, coat 2: $1 \mathrm{~T} 2+1,5 \mathrm{~S}+1,5 \mathrm{G}(0<\phi<2 \mathrm{~mm})+1 / 2$ cow dung $+1 / 8$ straw approx. $+1 / 8$ gravel $(2<\phi<20 \mathrm{~mm})$ approx.

All the applied techniques and the tested recipes for the rendering and plastering on the wall gave satisfying results both in terms of finishing and performance.

Such tests confirm the fact that improving the mud-based plaster mixes by controlling the quantity and the quality of the sand fraction in the local soil and adding specific tempers, provides a perfectly suitable product for the protective coating of earthen heritage structures. Moreover, these mixes fulfil the aims of using locally available materials and respect the physical, hygroscopic and aesthetic characteristics of the original materials while using and perpetuating the traditional techniques. For such reasons, this protocol represents a valid alternative to the use of the simple clay and straw mix, previously used in the restoration works at the site.

\section{THE IMPORTANCE OF TRADITIONAL TECHNIQUES: RECOVERY AND DIFFUSION}

Earthen architecture is one of the most original and powerful expressions of man's ability to create a built environment with readily available resources. Attention to cultural roots, conservation and care of the built heritage are constitutive elements for the harmonious development of modern Omani society and are also the prerequisites for future life. In creating the balance between past and future it is possible to allow this unique cultural landscape to regain its meaning and serve its inhabitants to their advantage.

\subsection{The loss of oral history}

Even in the twenty-first century, despite the development of modern educational methods, oral narrations should continue to be an important tool in handing down the know-how of traditional construction techniques, architecture and material culture. Without doubt, oral history has to be considered a primary source for historical information. It is, therefore, urgent to learn (and store the information) from old Omani craftsmen, the only holders of the knowledge related to these traditional mudbrick-making techniques, before this wisdom fades away without any new apprentices following in their wake. Against this background, the comprehensive, multi-media documentation work of all the phases and techniques involved in traditional mud-based architecture that was mentioned above takes on further relevance.

In Oman traditional tales, the theory underlying material culture, were until modern times passed on from person to person and, generally, directly taught from the old craftsman to younger ones who will become the co-creators of the conservation messages to be passed on (Ogega, 2011).

However, since the 1970s, the civil and cultural revolution (the 'Omani Renaissance'), which after years of obscurantist isolation has been led by Sultan Qābūs bin Sa'îd Āl Sa'īd, has allowed the formation of what is called 'modern Oman', promoting a policy 
of modernisation and tolerance that led the Sultanate to have one of the highest development rates in the world.

For millennia the socio-economic model based on inland oases constituted the backbone of Omani society, as shown by evidence dating as early as the $3^{\text {rd }}$ millennium BC. The above mentioned transformations in the everyday culture, especially in the internal areas of the country where settlement was tightly connected with the existence of such oases as an indivisible combination of housing and work, are the causes of the partial or total abandonment of historic villages, and the irreparable consequent loss of the need to continue to maintain the efficiency of traditional houses made of mudbricks and protected by mud-and-straw plaster (Mershen, 2010).

Given this scenario, the younger generations are no longer encouraged to learn the traditional building techniques, even going so far as to refuse their teaching, as masonry is seen as a profession that is no longer dignified.

\section{CONCLUSION}

This paper illustrates the process that led to a defined conservation strategy for Salūt, a key-site for Southeast Arabian prehistory, through a multidisciplinary approach, primarily via collaboration between architects and archaeologists. This process started with an accurate photogrammetric documentation phase and, step by step, arrived at an awareness of the use and improvement of traditional techniques for providing the best intervention solutions and defining a feasible plan of systematic maintenance. Actually preventive maintenance, along with the procedures adopted during excavation, is a key factor in having a large scale conservation plan. For this reason one of the most important aspects of the project has been the empirical experiments on plaster mix to be tested during a reasonable period of use, before being adopted on a wider scale. This may represent without fail, one of the future aims. The reintroducing of earthen traditional techniques, and exploiting the life-long experience in mud-based masonry of a local mason, turned out to be the best way for providing an opportunity to revive knowledge of this technique, with its associated materials and local terminology. This conservation strategy, firstly, is highly sustainable and, secondly, by recording interviews and shooting videos of every step of the work of a local mason, it encourages younger Omani to study and re-appropriate a traditional heritage that is suddenly disappearing. This can be adopted in future aims involving such materials in disseminating public information on this site. Reviving traditions is a keystrategy for site management and community involvement. Thus this comprehensive restoration programme, has given positive results in different directions that could represent such guidelines to be followed for promoting and defining the recovery of the archaeological sites of the whole Sultanate.

\section{ACKNOWLEDGEMENTS}

The authors would like to thank Prof. A. Avanzini, Director of the IMTO, who promoted the restoration works over all these years. Works at Salūt were made possible by the invaluable support of the Office of HE the Adviser to HM the Sultan for Cultural Affairs - Muscat.

\section{REFERENCES}

Avanzini, A, Degli Esposti, M. (eds.), 2018. Husn Salūt and the Iron Age of South East Arabia. Excavations of the Italian Mission to Oman 2004-2014. (Arabia Antica 15). L"'Erma" di Bretschneider, Roma.

Bizzarri, S., 2015. Restoration works at Salūt. In Avanzini, A. (ed.), In the heart of Oman. The castle of Salüt. (Ancient Oman, 1). Rome: L"'Erma" di Bretschneider, Roma, 87-95.
Condoluci, C., 2018. The Iron Age architecture of Husn Salūt. In Avanzini, Degli Esposti, 2018, 201-277.

Degli Esposti, M. 2015. Two thousands years of settlement at Salūt (c. 2300-300 BC). In the heart of Oman. The castle of Salüt. (Ancient Oman, 1). Rome: L'"Erma" di Bretschneider, Roma, 55-66.

Degli Esposti M, Condoluci C. Husn Salūt in the Iron Age. In Avanzini, Degli Esposti, 2018, 33-91.

Degli Esposti M, Condoluci C, Phillips C. Salūt during the Islamic period. In Avanzini, Degli Esposti, 2018, 383-399.

Dehkordi, M. H., Vatandoust, R., Madjidzadeh, Y., Kashi, M. G., 2008. The archaeological site of Konar Sandal, Jiroft, Iran: Conservation of earthen architecture. Terra 2008. The Getty Conservation Institute, Los Angeles, 183-188.

Doat, P., Hays, A., Houben, H., Matuk, S., Vitouxeds, F., 1983. Construire en terre. Editions Alternatives, Paris.

Hago, A. W., Al-Rawas, A., 1997. Properties Of The Omani Sarooj. Engineering Journal of University of Qatar, 10, 81-91.

Meddah, M.S., Benkari, N., Al-Busaidi, M., 2019. Potential Use of Locally and Traditionally Produced Bending Construction Material. IOP Conf. Series: Materials Science and Engineering, 471. doi:10.1088/1757-899X/471/4/042008

Mershen, B., 2010. Unveiling the Past: the Role of Oral History in Understanding Oasis Development. Oases of Oman. Livelihood System at the crossroads. Al Roya Press \& Publishing House, Muscat, 60-63.

Ogega, J. J., 2011. Oral Traditions in the Conservation of Earthen Architecture. Terra 2008. The Getty Conservation Institute, Los Angeles, 124-128.

Petzet, M., 2004. Principles of preservation: An introduction to the International Charters for Conservation and Restoration 40 years after the Venice Charter. In Petzet, M., Ziesemer, J. (eds.), International Charters for Conservation and Restoration. Monuments \& Sites, I. ICOMOS, München, 7-29.

Prati, G.L., 2000. Manualetto pratico illustrato della architettura in terra cruda riferito al caso alessandrino. https://www.comune.alessandria.it/servizi/lavori-pubblici-eurbanistica/manualetto-pratico-illustrato-dellarchitettura-interra-cruda-riferito-al-caso-alessandrino (15 January 2020).

Rainer, L., 2008. Deterioration and pathology of earthen architecture. Terra Literature Review: An Overview of Research in Earthen Architecture Conservation. The Getty Conservation Institute, Los Angeles, 45-61.

Ruskulis, O., 2009. Mud Plasters and Renders. Appropriate Technology Journal. https://answers.practicalaction.org/ourresources/item/mud-plasters-and-renders (15 January 2020).

Sassu, M., Zarins, J., Giresini, L., Newton, L., 2017. The 'Triple R' Approach on the Restoration of Archaeological Dry Stone City Walls: Procedures and Application to a UNESCO World Heritage Site in Oman. Conservation and Management of Archaeological Sites, 19/2, 106-125.

\section{CREDITS}

Bizzarri, S., photos and 3D models, Figures 1, 2, 3, 4, 5, Mummolo, F., photo Figure 6,

Tangheroni, E., photo Figure 10. 